\title{
Rancang Bangun Animasi 3 Dimensi Penyebab Kecelakaan Lalu Lintas (Studi Kasus: Polres Bolaang Mongondow)
}

\author{
I Made Andika Sanjaya, Arie S.M. Lumenta, Brave A. Sugiarso \\ Teknik Informatika Universitas Sam Ratulangi. Manado, Indonesia \\ imadeandikasanjaya93@gmail.com, al@unsrat.ac.id, brave@unsrat.ac.id
}

\begin{abstract}
Abstrak - Kabupaten Bolaang Mongondow memiliki tingkat kecelakaan lalu lintas yang cukup tinggi tiap tahunya, menurut data penyebab kecelakaan lalu lintas yang diperoleh dari satuan lalu lintas Polres Bolaang Mongondow, pada bulan januari 2015 sampai agustus 2015, sudah terjadi 301 kasus kejadian kecelakaan lalu lintas yang di sebabkan oleh pengemudi yang lengah atau kurang berkonsentrasi saat sedang mengemudi. Melakukan aktivitas seperti menggunakan HP (handphone), mengambil makanan/minuman, dan mengobrol saat sedang mengemudi adalah faktor utama yang menyebabkan pengemudi lengah atau kurang berkonsentrasi.
\end{abstract}

Animasi 3D merupakan animasi yang berwujud tiga dimensi meskipun bukan dalam bentuk 3D yang sebenarnya, yaitu bukan fisiknya, namun dalam wujud 3D dalam layar kaca 2D. Tidak seperti animasi 2D yang memiliki dimensi panjang $X$ dan lebar $Y$, animasi 3D selain memiliki ke dua dimensi tersbut juga memiliki dimensi kedalaman $\mathrm{Z}$.

Tujuan dari penelitian ini adalah untuk membuat video animasi 3 dimensi penyebab kecelakaan lalu lintas sebagai sarana informasi untuk masyarakat tentang bahaya melakukan aktivitas seperti menggunakan HP (handphone), mengambil minuman/makanan, dan mengobrol saat sedang mengemudi yang dapat menyebabkan pengemudi lengah, dan berakibat pada kecelakaan lalu lintas.

Pembuatan video animasi 3 dimensi ini, dimulai dengan tahap pengumpulan data, penentuan ide dan tema, desain karakter hingga perancangan storyboard. setelah itu dilakukan proses modelling, texturing, rigging animating, $3 d$ visual effects, lighting hingga tahap rendering, dengan menggunakan aplikasi Blender dan Makehuman yang kemudian menghasilkan beberapa potongan-potongan video animasi 3 dimensi. Setelah proses rendering selesai, tahap selanjutnya adalah final editing, dimana semua hasil video animasi 3 dimensi yang telah selesai dibuat sebelumnya pada aplikasi blender, akan disatukan dan diberikan teks, gambar, efek transisi, serta audio dengan menggunkaan aplikasi corel video studio pro x6. Tahap terakhir adalah final rendering yang menghasilkan video animasi 3 dimensi secara keseluruhan dengan format file MP4, durasi 5 menit 53 detik, beresolusi 1920x1080 pixel dan ukuran file $423 \mathrm{MB}$.

Kata kunci: Animasi 3D, Blender, Penyebab Kecelakaan Lalu lintas.
Abstract - The county of Bolaang Mongondow had high enough the rate of traffic accidents every year, according to the cause of traffic accidents data which is gotten from Police Bolaang Mongondow's Traffic Unit on January 2015 until August 2015. It has happened 301 cases of the traffic accident incident caused by drivers who are careless or less concentrate while driving. Doing activities like using handphone, take foods or drinks, and chatting while driving are main factors that caused the driver careless or less the concentration. The purpose of the research is to make the 3D animated video the cause of traffic accidents as a means of information to the citizens like using handphone, take foods or drinks, and chatting while driving that can cause driver dally, have consequence in a traffic accident. Making 3D animated video is started with data collection, decide idea and theme, the character design until storyboard. After that made the process of modeling, texturing, rigging animating, 3D visual effects, lighting until rendering step by using Blender application and Makehuman then produced a few pieces of 3D animation video. After rendering process has finished, the next step is final editing where all the results of 3D animated video has been completed made before on the Blender application, will pieced together and give the texts, picture, transition effect, and audio by using corel studio video x6 application. The last step is final rendering which producing $3 D$ animated video overall with the format file MP4, the duration 5 minutes 53 seconds, the resolution 1920x1080 pixel, and the size of the file is $423 \mathrm{MB}$.

Key Words : 3D Animation, Blender, The Cause of Traffic Accidents.

\section{PENDAHULUAN}

Kendaraan bermotor adalah salah satu sarana transportasi penting bagi kehidupan manusia untuk memperlancar berbagai aktivitas sehari - hari. Selain itu kendaraan bermotor juga dapat mengakibatkan dampak yang buruk bagi manusia, yaitu kecelakaan lalu lintas yang mengakibatkan cacat fisik, kerugian material, bahkan kematian. Terdapat beberapa faktor yang menjadi penyebab kecelakan lalu lintas, salah satunya adalah pengemudi yang lengah atau kurang berkonsentrasi saat sedang mengemudi yang menjadi faktor terbesar terjadinya kecelakaan lalu lintas. Melakukan aktivitas seperti menggunakan HP 
(handphone), mengobrol, mengambil minuman dan makanan saat sedang mengemudikan kendaraan adalah penyebab terjadinya lengah atau berkurangnya konsentrasi pengemudi.

Kepolisian sebagai pihak yang berwajib, sudah melakukan segala upaya untuk mewujudkan lalu lintas yang aman dan tertib, dengan mengadakan sosialisasi dalam bentuk media cetak maupun media elektronik sebagai contoh melalui iklan layanan masyarakat tentang tata tertib berlalu lintas. Namun masih kurangnya kesadaran dan pemahaman masyarakat akan ketertiban dan keselamatan dalam berlalu lintas. Hal tersebutlah yang menjadi kendala utama dalam mewujudkan tujuan sosialisasi ini.

Tidak berbeda dengan kabupaten lainya di Indonesia, kabupaten Bolaang Mongondow juga memiliki tingkat kecelakan yang cukup tinggi tiap tahunya. Menurut data yang di peroleh dari satuan lalu lintas polres Bolaang Mongondow, pada tahun 2015 sudah terjadi 368 kejadian kecelakaan lalu lintas di jalan raya. Terhitung sejak januari 2015 sampai agustus 2015, sebanyak 301 kasus kejadian kecelakaaan yang disebabkan oleh pengemudi yang lengah atau kurang berkonsentrasi saat mengemudikan kendaraan yang mendominasi kecelakaan lalu lintas di kabupaten Bolaang Mongondow. Berdasarkan data tersebut penulis tertarik untuk membuat sarana informasi untuk masyarakat melalui Rancang Bangun Animasi 3 Dimensi penyebab kecelakaan lalu lintas. Animasi 3 dimensi yang dibuat akan membahas tentang penyebab kecelakaan lalu lintas yang diakibatkan oleh pengemudi yang melakukan aktivitas seperti menggunakan HP, megobrol dan mengambil minuman saat sedang mengemudi yang menyebabkan pengemudi lengah atau kurang berkonsentrasi dan mengakibatkan kecelakaan lalu lintas.

Berdasarkan latar belakang masalah yang telah penulis uraikan diatas maka penulis ber-inisiatif untuk membuat sarana informasi untuk masyarakat tentang bahaya melakukan aktivitas saat sedang berkendara yang menyebabkan kecelakaan lalu lintas, melalui Rancang Bangun Animasi 3 Dimensi Penyebab Kecelakaan Lalu Lintas ( Studi Kasus : Polres Bolaang Mongondow ).

\section{A. Rumusan Masalah}

Berdasarkan latar belakang yang telah di paparkan sebelumnya, maka dapat dirumuskan msalah yaitu:

- Bagaimana cara memberikan informasi kepada masyarakat tentang bahaya melakukan aktivitas seperti menggunakan HP, mengobrol dan mengambil minuman saat sedang mengemudi yang dapat menyebabkan pengemudi lengah atau kurang berkonsentrasi dan mengakibatkan kecelakaan lalu lintas.

- Bagaimana cara membuat sosialisasi yang menarik dan mudah di pahami oleh masyarakat untuk mengurangi tingginya angka kecelakaan lalu lintas yang terjadi di kabupaten Bolaang Mongondow.

- Bagaimana membuat animasi 3 dimensi yang berisikan penyebab kecelakaan lalu lintas yang terjadi di wilayah polres Bolaang Mongondow.

\section{B. Batasan Masalah}

Adapun batasan masalah dalam penelitian ini adalah:

- Dalam pembuatan animasi 3 dimensi penyebab kecelakaan lalu lintas ini penulis menggunakan software blender v2.76, MakeHuman v1.0.2, dan corel video studio pro $\mathrm{x} 6$

- Animasi 3 dimensi penyebab kecelakaan lalu lintas yang dibuat hanya berdasarkan data penyebab kecelakaan lalu lintas tertinggi yang telah diperoleh dari satuan lalu lintas Polres Bolaang Mongondow, yaitu pengemudi yang lengah saat sedang mengemudi karena menggunakan HP, mengambil minuman dan mengobrol saat sedang mengemudi.

- Studi kasus penelitian ini dilaksanakan di Polres Bolaang Mongondow.

\section{Tujuan}

Tujuan dari penelitian ini adalah untuk membuat video animasi 3 dimensi penyebab kecelakaan lalu lintas sebagai sarana informasi untuk masyarakat tentang bahaya melakukan aktivitas yang dapat mengganggu konsentrasi pengemudi seperti menggunakan HP, mengobrol dan mengambil makan/minuman saat sedang mengemudi yang menyebabkan pengemudi lengah dan berakibat pada kecelakaan lalau lintas.

\section{Manfaat Penelitian}

Adapun manfaat dari penelitian ini antaralain:

- Dengan adanya sosialisai dalam bentuk video animasi 3 dimensi ini diharapkan dapat membantu masyarakat untuk lebih mudah memahami dampak buruk melakukan aktivitas seperti menggunakan HP, mengobrol dan mengambil minuman saat sedang mengemudi yang dapat menyebabkan pengemudi lengah dan berakibat pada kecelakaan lalu lintas.

- Dengan adanya sosialisasi ini, diharapkan dapat mengurangi tingginya angka kecelakaan lalu lintas yang terjadi di kabupaten Bolaang Mongondow.

\section{LANDASAN TEORI}

\section{A. Definisi Multimedia}

Secara harfiah, kata "multimedia" terdiri dari kata 'multi' yang berarti banyak dan 'media' yang berarti alat atau sarana untuk menyampaikan informasi sehingga multimedia dapat dikaitkan dengan elemen media yang 
digabungkan. Dengan demikian, pengertian multimedia adalah penyajian dari suatu aplikasi komputer, biasanya interaktif, yang menggabungkan elemen media seperti teks, grafik, video, animasi, dan suara pada komputer. McGlounghlin(dalam Handayani T.K 2011). ${ }^{[6]}$

\section{B. Definisi Animasi}

Animasi berasal dari kata "to animate” yang artinya menggerakan. Animasi sendiri merupakan suatu teknik menampilkan gambar berurutan sedemikian rupa sehingga penonton merasakan adanya ilustrasi gerakan (motion) pada gambar yang ditampilkan. Animasi adalah hasil dari proses menampilkan objek-objek gambar sehingga gambar yang ditampilkan akan tampak hidup. Tidak hanya menghidupkan, animasi juga memberikan karakter kepada objek-objek tersebut. Binanto(dalam Paramitha A.I, 2014). ${ }^{[8]}$

\section{Animasi 3 Dimensi}

Animasi 3D adalah animasi yang berwujud tiga dimensi meskipun bukan dalam bentuk 3D yang sebenarnya, yaitu bukan fisiknya, namun dalam wujud 3D dalam layar kaca 2D (layar tv, bioskop, komputer, proyektor, dan media sejenisnya). Tidak seperti animasi 2D yang memiliki dimensi panjang $(\mathrm{X})$ dan lebar $(\mathrm{Y})$, animasi 3D selain memiliki ke dua dimensi tersbut juga memiliki dimensi kedalaman (Z). Aditya (dalam Paramitha A.I. 2014). ${ }^{[8]}$

\section{Lalu Lintas}

Menurut pasal 1 angka 1 UULLDAJ, Lalu lintas dan angkutan jalan adalah satu kesatuan sistem yang terdiri atas lalu lintas, angkutan jalan, jaringan lalu lintas dan angkutan jalan, prasarana lalu lintas dan angkutan jalan, kendaraan, pengemudi, pengguna jalan, serta pengelolanya. ${ }^{[2]}$

\section{E. Kecelakaan Lalu Lintas}

Menurut pasal 1 angka 24 UULLDAJ, Kecelakaan lalu lintas adalah suatu peristiwa di jalan yang tidak diduga dan tidak disengaja melibatkan kendaraan dengan atau tanpa Pengguna Jalan lain yang mengakibatkan korban manusia dan atau kerugian harta benda $^{[2]}$.

\section{F. Faktor Kecelakaan Lalu Lintas}

Warpani dkk (dalam Adnan S. 2010) ${ }^{[1]}$ menyebutkan bahwa kecelakaan lalu-lintas pada umumnya terjadi karena berbagai faktor penyebab secara bersama-sama, yakni manusia, kondisi jalan, kondisi kendaraan, cuaca, pandangan terhalang dan faktor-faktor lain.

\section{G. Blender $3 D$}

Blender 3D adalah software gratis yang bisa digunakan untuk modeling, texturing, lighting, animating dan video post processing 3 dimensi. Blender 3D yang merupakan software gratis dan open source ini merupakan open source 3D paling populer di dunia. Fitur Blender 3D tidak kalah dengan software 3D berharga mahal seperti 3D studio Max, Maya maupun XSI. Dengan Blender 3D anda bisa membuat objek 3D animasi, media 3D interaktif, model dan bentuk 3D profesional, membuat objek game dan masih banyak lagi kreasi 3D lainnya. ${ }^{[4]}$

\section{H. MakeHuman}

MakeHuman adalah aplikasi membuat model tubuh manusia secara utuh dan detail. Dapat digunakan pada sistem operasi Linux, Windows, dan MAC OS. Proses pembuatan postur tubunh manusia dimulai dengan pemilihan beberapa kategori, seperti etnis, gender, usia, bentuk tulang, bentuk tubuh tertentu, dll. Setiap fitur dalam aplikasi ini dibuat sedemikian rupa untuk menyesuaikan dengan kebutuhan anda. ${ }^{[7]}$

\section{Corel Video Studo $x 6$}

Corel Video Studio adalah paket perangkat lunak editing video untuk Microsoft Windows, yang didistribusikan oleh ulead system ( sebuah divisi dari corel ). Corel Video Studio adalah software terlengkap yang menggabungkan beberapa visual efek yang luar biasa. Dengan Corel Videos tudio kita bisa membuat video dengan kualitas HD. Penggunaan yang mudah dan sangat menarik untuk digunakan menjadikan Corel Video Studio menjadi daya tarik tersendiri bagi para editor.

\section{J. Alur Kerja Produksi Animasi 3D}

Menurut Kerlow (dalam Chan k. 2007) ${ }^{[5]}$ Pembuatan sebuah film animasi melalui berbagai proses, dimulai dari penentuan konsep cerita dan pembuatan storyboard. Setelah konsep ditentukan proses selanjutnya adalah dengan proses pengambilan gambar yang dipecah menjadi beberapa komponen seperti modelling, rigging, animasi, dan lain sebagainya. Agar hasil akhir dapat tercapai maka semua bagian dalam alur kerja tersebut haruslah saling berkaitan, alur kerja inilah yang disebut sebagai Pipeline. Alur kerja atau pipeline terbagi kedalam tiga tahapan kerja, yaitu Pra produksi, Produksi, dan Pasca produksi. Namun perlu diketahui bahwa tahapan membuat karya animasi ini bisa saja berbeda urutan dan perlakuannya, tergantung pada kebiasaan tiap studio animasi. tiap studio animasi memiliki pipeline sendiri tergantung dari cara kerja yang dianggap paling efisien. Alur kerja atau pipeline terbagi kedalam tiga tahapan kerja diantaranya Pra produksi, Produksi, dan Pasca produksi. ${ }^{[3]}$

\section{METODOLOGI PENELITIAN}

\section{A. Metode Perancangan}


Dalam perancangan animasi 3 dimensi penyebab kecelakaan lalu lintas ini penulis menggunakan tiga tahapan perancangan animasi yang terdiri dari: Tahap Pra-Produksi, Tahap Produksi dan Tahap Pasca Produksi seperti pada gambar 1

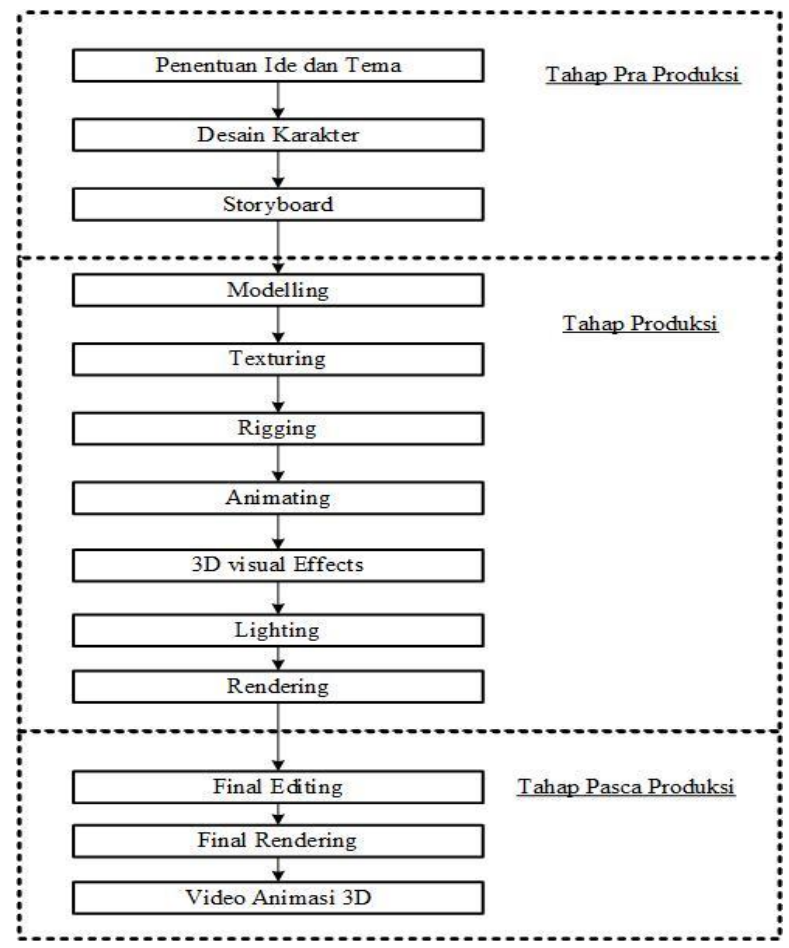

Gambar 1. Alur perancangan animasi 3D

- Tahap pra produksi

Adapun kegiatan-kegiatan yang dilakukan dalam tahap pra produksi antaralain:

- Penentuan ide dan tema cerita dari video animasi 3 dimensi penyebab kecelakaan lalu lintas ini didapatkan dari data penyebab kecelakaan lalu lintas yang telah diperoleh dari satuan lalu lintas Polres Bolaang Mongondow dan hasil konsultasi dengan beberapa dosen pembimbing sehingga menjadi judul skripsi Rancang Bangun Animasi 3 Dimensi Penyebab Kecelakaan Lalu Lintas ( studi kasus: Polres Bolaang Mongondow ). Dalam video animasi 3 dimensi ini memceritakan tentang penyebab kecelakaan lalu lintas yang di akibatkan oleh pengemudi yang lengah atau kurang berkonsentrasi saat mengemudi, karena melakukan aktivitas seperti menggunakan HP, mengobrol, dan mengambil minuman saat sedang mengemudi.

- Desain karakter. Pada komponen desain ini bentuk akhir sebuah animasi sudah ditetapkan, yang termasuk dalam komponen ini adalah rancangan karakter, property,lingkungan serta kostum yang akan dikenakan oleh karakter.
- Storyboard. Setelah penetuan ide dan tema, kemudian pembuatan desain karakter, proses selanjutnya adalah menuangkan ide tersebut kedalam bentuk storyboard agar nantinya proses pembuatan animasi 3 dimensi penyebab kecelakaan lalu lintas akan lebih mudah dan terarah seperti pada tabel I, II, dan III

TABEL I. STORYBOARD KECELAKAAN LALU LINTAS AKIBAT PENGEMUDI MENGGUNAKAN HP SAAT SEDANG MENGEMUDI

\begin{tabular}{|c|c|c|}
\hline No. & Gambar & Penjelasan \\
\hline 1. & $\begin{array}{c}\text { Sambil mengemudikan } \\
\text { kendaraan, pengemudi } \\
\text { sibuk mebaca pesan dan } \\
\text { tidak berkonsentrasi } \\
\text { kedepan. }\end{array}$ \\
\hline 2 & $\begin{array}{c}\text { Pengemudi tidak } \\
\text { memperhatikan lampu } \\
\text { lalu lintas dan kendaraan } \\
\text { lain yang sedang } \\
\text { melintasi persimpangan } \\
\text { karena sibuk mebaca } \\
\text { pesan. }\end{array}$ \\
\hline 3. & $\begin{array}{r}\text { Pengemudi menabrak } \\
\text { kendaraan didepan yang } \\
\text { sedang melintas. }\end{array}$ \\
\hline
\end{tabular}

TABEL II. STORYBOARD KECELAKAAN LALU LINTAS AKIBAT PENGEMUDI MENGOBROL DENGAN PENUMPANG SAAT SEDANG MENGEMUDI

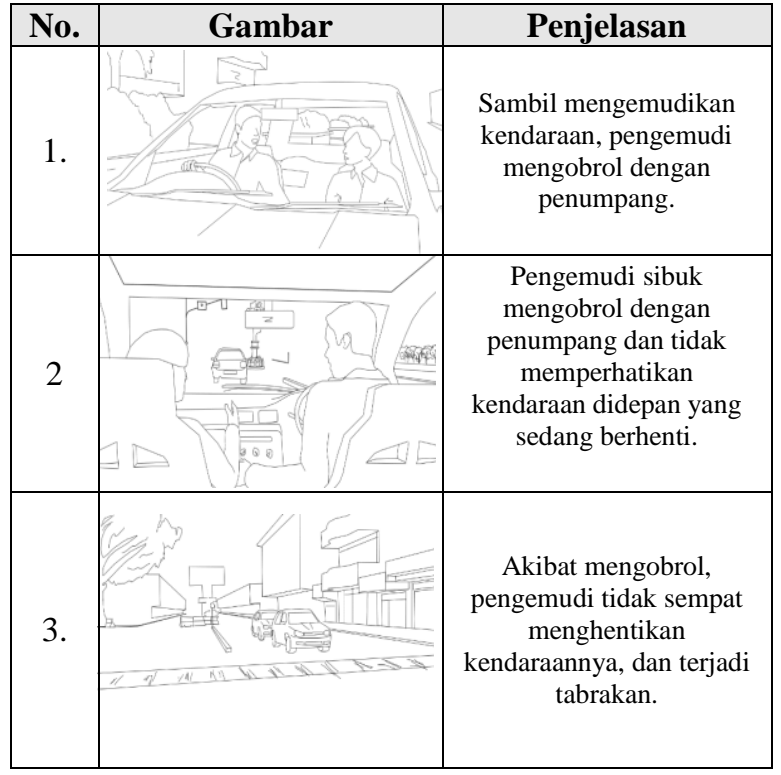


TABEL III. STORYBOARD KECELAKAAN LALU LINTAS AKIBAT PENGEMUDI MENGAMBIL MINUMAN SAAT SEDANG MENGEMUDI

\begin{tabular}{|c|c|c|}
\hline No. & Gambar & $\begin{array}{c}\text { Penjelasan } \\
\text { Akibat mengambil } \\
\text { minuman saat sedang } \\
\text { mengemudi, pengemudi } \\
\text { tidak menyadari ada } \\
\text { kendaraan lain didepan } \\
\text { yang berjalan dengan } \\
\text { lambat. }\end{array}$ \\
\hline 2 & & $\begin{array}{c}\text { Pengemudi terkejut dan } \\
\text { mencoba membanting } \\
\text { setir mobil karena mobil } \\
\text { akan menabrak kendaraan } \\
\text { didepan. }\end{array}$ \\
\hline 3. & & $\begin{array}{c}\text { Pengemudi menabrak } \\
\text { kendaraan didepannya } \\
\text { karean sudah tidak } \\
\text { sempat menghindar. }\end{array}$ \\
\hline
\end{tabular}

\section{HASIL DAN PEMBAHASAN}

\section{A. Tahap Produksi}

\section{- $\quad$ Modeling}

Pada perancangan dan pembuatan video animasi 3 dimensi penyebab kecelakaan lalu lintas ini penulis menggunakan objek Plan, Cube, UV spare, cylinder dan torus. Selanjutnya proses pembentukan objek dilakukan pada Edit Mode dengan menggunakan fungsi Grab, Scale, Rotation, extrud dan beberapa tools editor seperti subdivision surface, array, solidify, dan mirror modifier yang terdapat pada aplikasi Blender, Sehingga pembentukan model objek dapat sesuai dengan keinginan penulis. Model objek yang dibuat terdiri dari objek mobil, pertokoan, trotoar, objek jalan, taman, tugu, lampi lalu lintas, pohon, handpone, botol minuman dan makanan seperti pada gambar 2 .

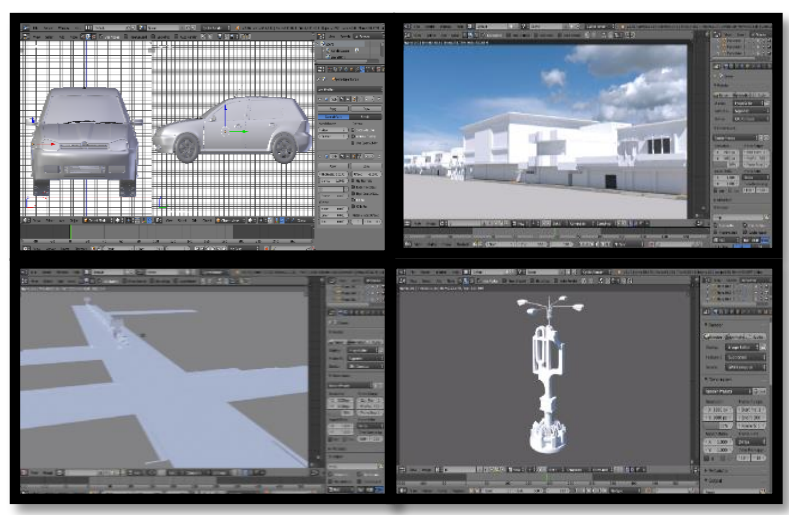

Gambar 2. Modeling objek pada aplikasi Blender
Selain itu juga, penulis membuat objek karakter manusia menggunakan aplikasi Makehuman, dimana dalam pembuatan objek karakter manusia, digunakan beberapa tools modeling yang disediakan oleh aplikasi MakeHuman yang terdiri dari main, gender, face, torso, arms and legs, custom, dan measure. tools-tools tersebut digunakan untuk membentuk bagian-bagian tubuh manusia sesuai dengan kebutuhan seperti pada gambar 3

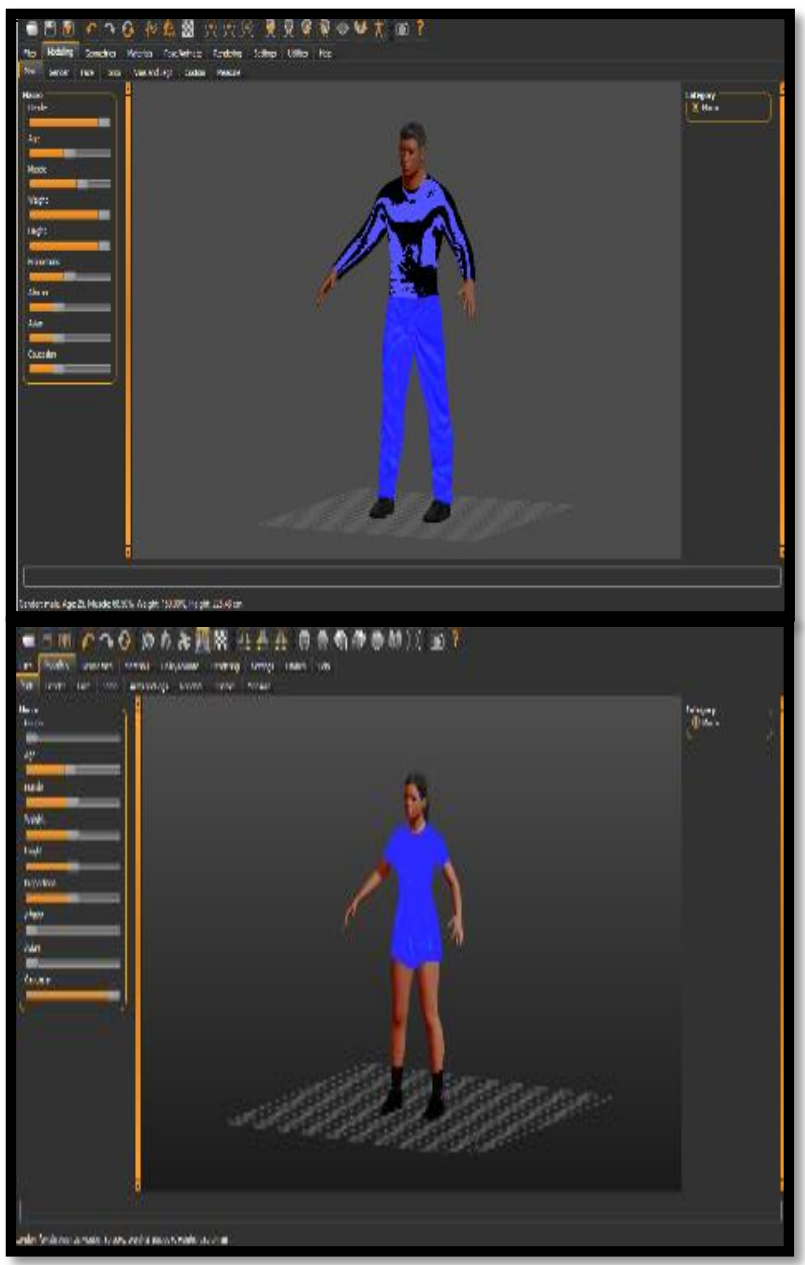

Gambar 3. Modeling objek manusia pada aplikasi MakeHuman

\section{- $\quad$ Texturing}

Pada proses texturing ini penulis menggunakan texsture atau warna yang sesuai dengan objek aslinya sehingga objek yang dibuat dapat terlihat lebih nyata dan menarik. Proses pemberian tekstur pada aplikasi Blender dengan menggunakan tools material yang terdapat pada panel properties, texsturing objek yang dibuat terdiri dari objek mobil, pertokoan, trotoar, objek jalan, taman, tugu, lampi lalu lintas, pohon, handpone, botol minuman dan makanan. Sedangkan untuk objek karakter manusia sudah tidak deberikan texture lagi, karena sudah tersedia dari aplikasi MakeHuman seperti pada gambar 4 


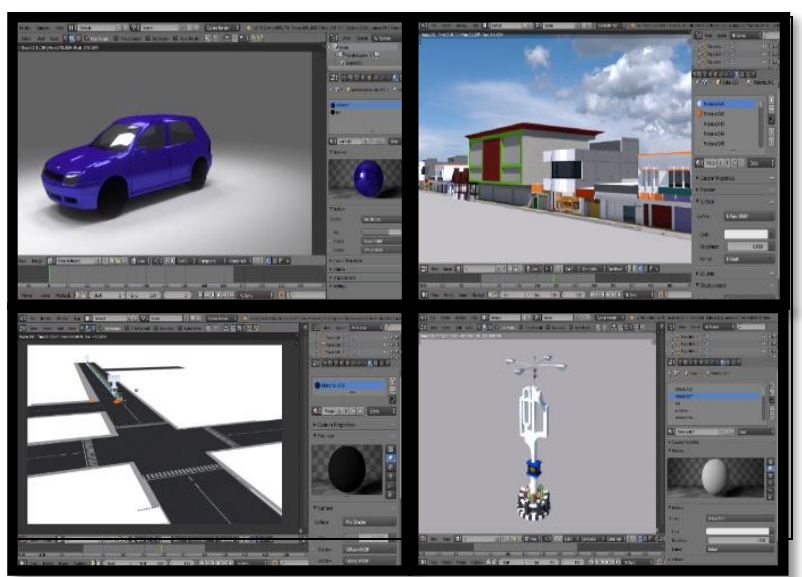

Gambar 4. Texturing objek pada aplikasi Blender

\section{- $\quad$ Rigging}

Pada tahap rigging ini penulis melakukan proses pemasangan tulang pada objek mobil dengan menggunakan addon car rig untuk mempermudah proses animating. penulis hanya perlu mengaktifkan $a d d$ on car rig pada tab file kemuidia pilih user preferences kemudian pilih tab addon dan pilih tab rigging selanjutnya aktifkan add on car rig dengan mencetang addon car rig. Setelah selesai mengaktifkan addon car rig proses selanjutnya adalah penyatuan tulang pada bagian-bagian bodi mobil dan juga pada roda mobil. Sedangkan untuk objek manusia proses rigging sudah tidak dilakukan lagi karena secara otomatis objek manusia yang dibuat melalui software MakeHuman telah diberikan rig atau tulang dan juga controller sperti pada gambar 5

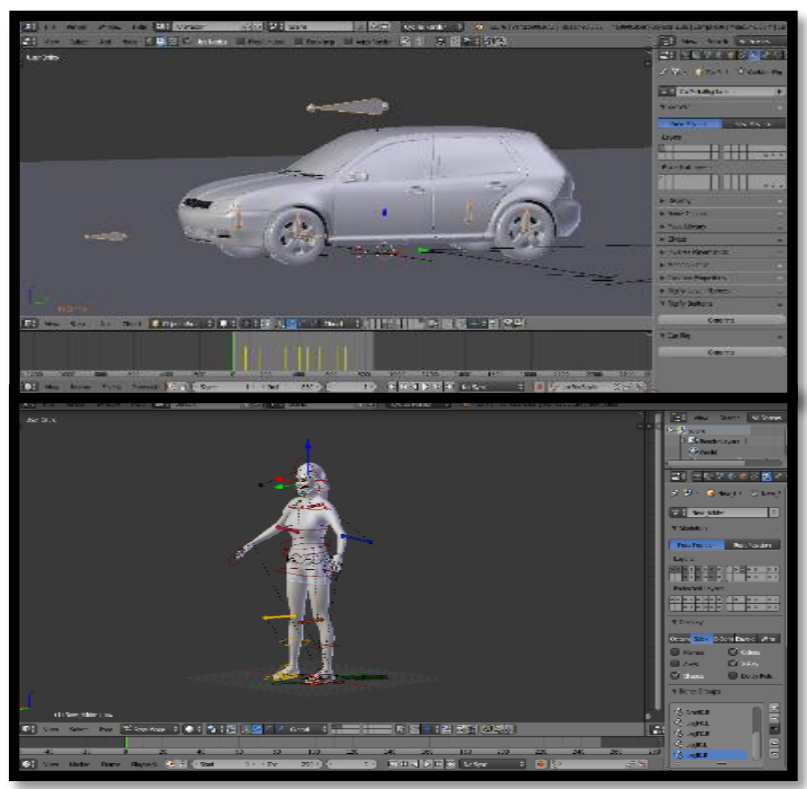

Gambar 5. Rigging objek mobil dan manusia

\section{- $\quad$ Animating}

Pada tahap animating ini penulis melakukan pengaturan gerakan pada objek karakter manusia, objek mobil, objek HP, objek botol minuman dan juga kamera sesuai dengan storyboard. Proses animating ini dilakukan secara manual dengan cara membuat pose terlebih dahulu terhadap objek, selanjutnya memberikan keyframe/kunci pose pada setiap objek di setiap frame yang telah diatur agar sesuai dengan storyboard yang telah dibuat seperti pada gambar 6

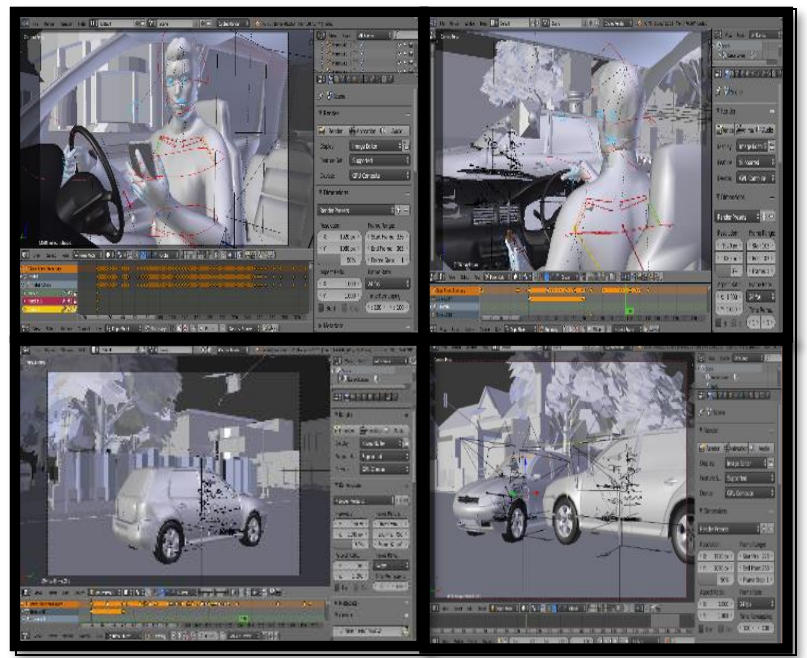

Gambar 6. Animating objek mobil dan manusia

\section{- 3D Visual effect}

Pada tahap ini penulis melakukan pemberian efekefek berupa kaca mobil yang pecah dan efek penyok pada bagian bodi mobil. Untuk membuat efek penyok pada bagian bodi mobil, penulis menggunakan tools shape key untuk membuat model penyok pada setiap bagian bodi mobil dan kemudian di animasikan. Sedangkan untuk membuat efek kaca pecah penulis menggunakan modifier explode untuk membuat pecahan pada objek kaca menjadi bagian kecil dan tools particle system yang berfungsi sebagai arah dari pecahan kaca seperti pada gambar 7

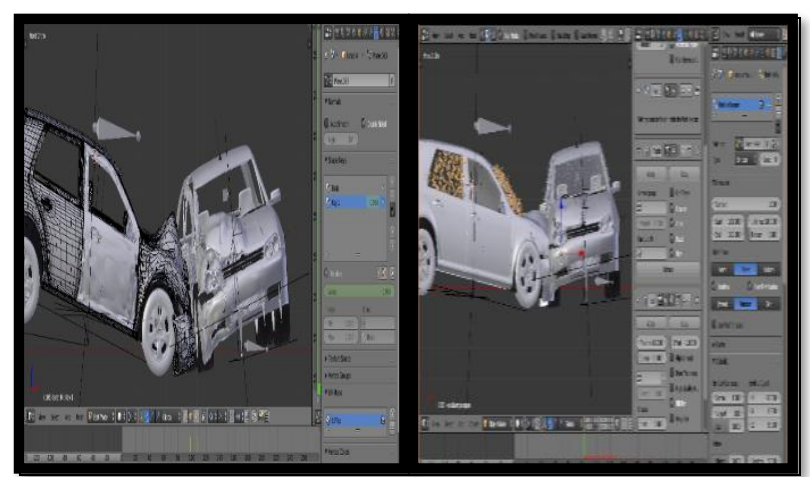

Gambar 7. Pemberian efek penyok dan pecahan kaca pada objek mobil 


\section{- $\quad$ Lighting}

Pada proses lighting ini penulis melakukan pemberian cahaya dengan menggunakan addon pro lighting skies. addon berfungsi untuk memberikan pencahayaan yang cahayanya datang dari segala arah secara global. Sedangkan untuk sumber cahayanya dari gambar HDRI (High Dynamic Range Imaging) berupa gambar langit 360 derajat. Proses ini bertujuan untuk meberikan hasil pencahayaan yang realistis seperti pada gambar 8

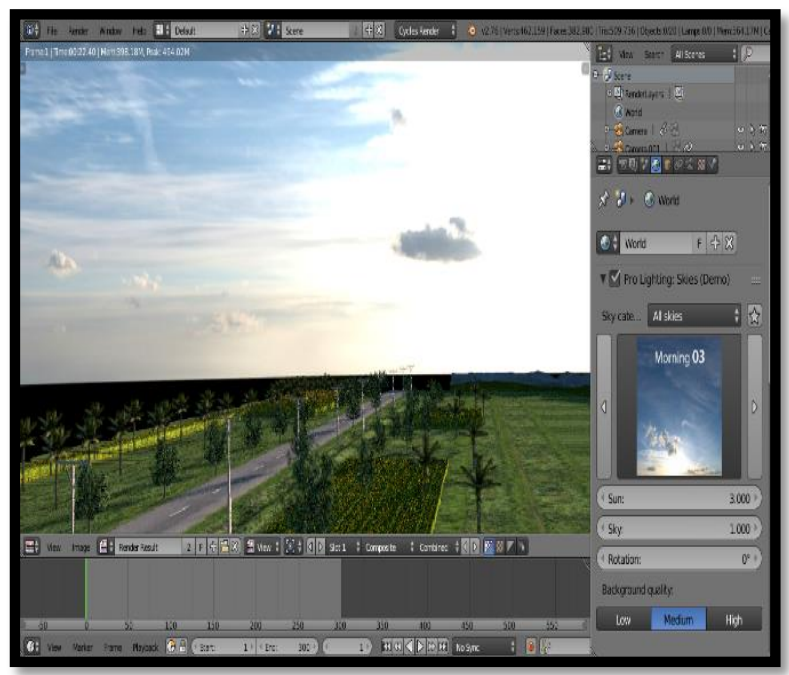

Gambar 8. Proses Lighting

\section{- Rendering}

Pada tahap rendering ini penulis melakukan proses rendering pada setiap adegan satu demi satu sehingga menghasilkam beberapa potong video animasi 3 dimensi dengan format output MP4. Proses rendering dilakukan pada kolom properties dengan menekan tombol animation pada tab render seperti pada gambar 9

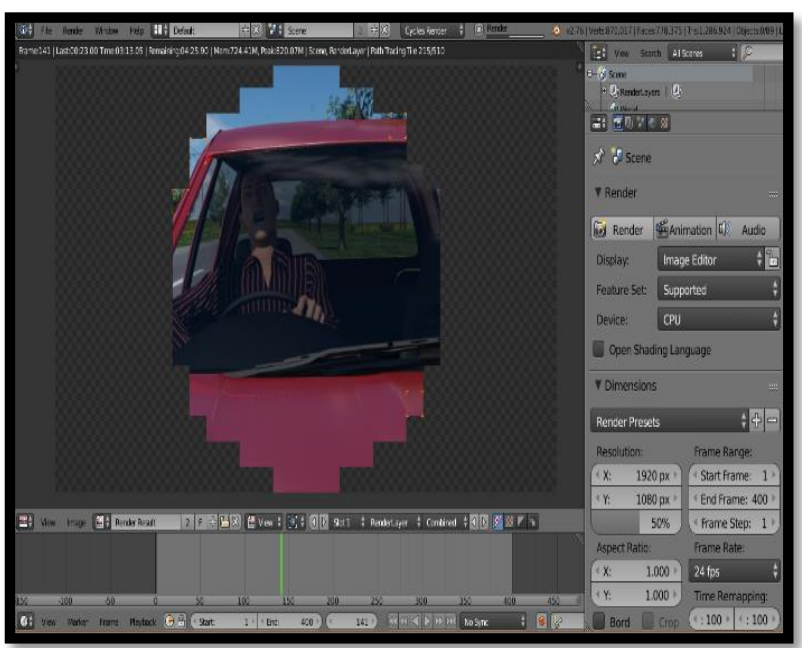

Gambar 9. Proses rendering dan video Hasil rendering aplikasi Blender

\section{B. Tahap Pasca Produksi}

- Final editing

Final editing adalah proses akhir dalam pembuatan video animasi 3 dimensi penyebab kecelakaan lalu lintas, dimana semua file video yang telah selesai di render pada aplikasi Blender, akan disatukan menjadi satu file utuh dan kemudian diberikan efek-efek berupa efek transisi, suara kendaraan mobil, efek suara tabrakan kendaraan, musik, pemberian teks, dan gambar dengan menggunakan aplikasi Corel Video Studio sperti pada gambar 10

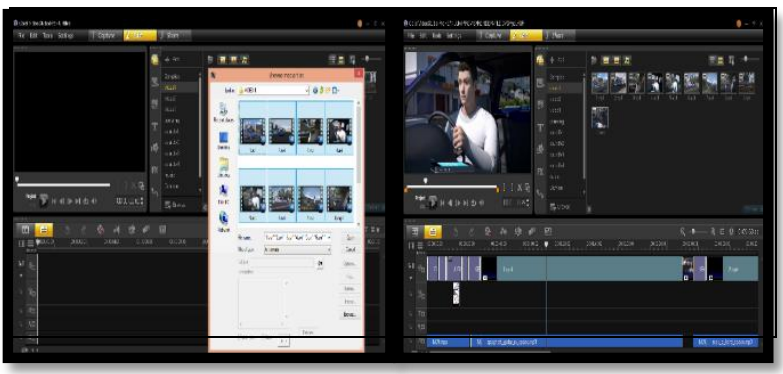

Gambar 10. Proses editing video dan suara pada aplikasi Corel Video Studio

\section{- $\quad$ Final Rendering}

Pada tahap ini merupakan tahap akhir dari pembuatan video animasi 3 dimensi penyebaba kecelakaan lalu lintas dimana pada tahap ini dilakukan proses penentuan resolusi video, format video dan selanjutnya meng-eksport video animasi 3 dimensi penyebab kecelakaan lalu lintas dengan menggunakan aplikasi Corel Video Studio. Pada proses penentuan resolusi video penulis menggunakan resolusi 1920x1080 pixel denga format MP4 seperti pada gambar 11

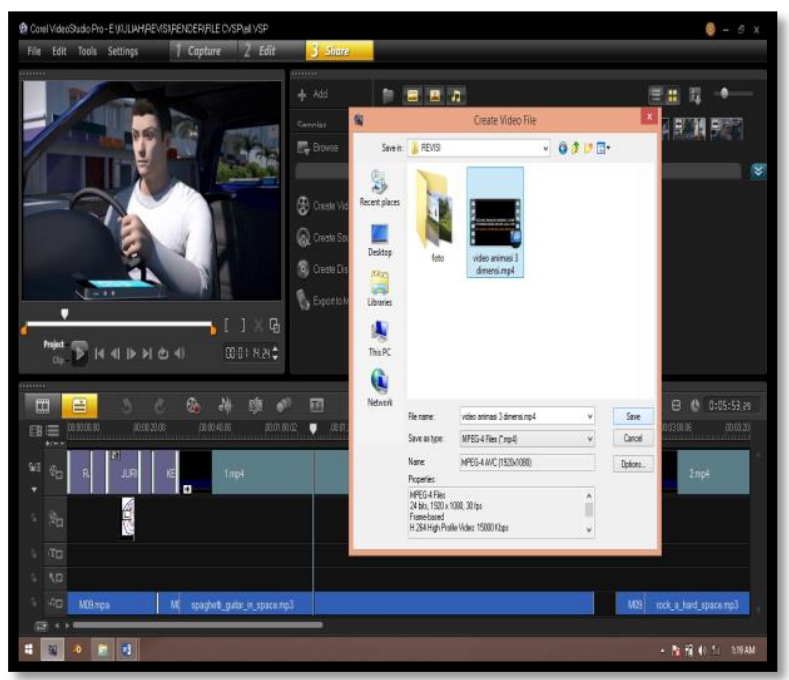

Gambar 11. Proses penentuan format video dan resolusi video 
- $\quad$ Hasil Video Animasi 3 Dimensi

Gambar 12 merupakan properties dan hasil dari video animasi 3 dimensi penyebab kecelakaan lalu lintas dengan format .MP4, resolusi 1920x1080 pixel, durasi 5 menit 53 detik dan ukuran file $423 \mathrm{MB}$.

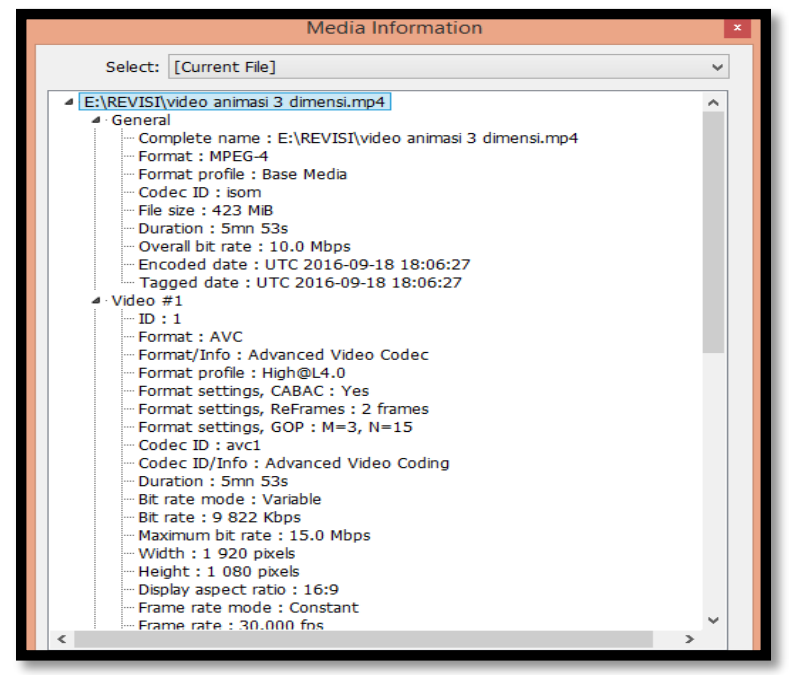

Gambar 12 Properties dan Hasil video animasi 3 dimensi penyebab kecelakaan lalu lintas.

\section{KESIMPULAN DAN SARAN}

\section{A. Kesimpulan}

Setelah menyelesaikan proses rancang bangun animasi 3 dimensi penyebab kecelakaan lalu lintas ini dapat disimpulkan bahwa:

- Proses pembuatan animasi 3 dimensi penyebab kecelakaan lalu lintas ini dapat diselesaikan dengan menggunakan alur produksi animasi 3D.

- Hasil akhir dari penelitian ini adalah video animasi 3 dimensi penyebab kecelakaan lalu lintas ( studi kasus : Polres Bolaang Mongondow ), dengan durasi 5 menit 53 detik, format file MP4 dan ukuran file $422 \mathrm{MB}$.

- Dengan adanya informasi dalam bentuk video animasi 3 dimensi ini, masyarakat dapat lebih mudah memahami dampak buruk melakukan aktivitas seperti menggunakan HP, mengobrol dan mengambil minuman saat sedang mengemudi yang dapat menyebabkan kecelakaan lalu lintas.

\section{B. Saran}

Saran yang ingin disampaikan untuk pengembangan yang lebih lanjut pada penelitian ini adalah sebagai berikut:

- Sebaiknya pada saat proses rendering, video yang dibuat dipecah menjadi beberapa bagian untuk memepercepat proses rendering.
- Dalam proses animating, dibutuhkan kesabaran dan ketelitian agar animasi yang dihasilkan dapat terlihat lebih halus.

- Dalam pembuatan animasi 3D dibutuhkan perangkat komputer yang memadai khususnya dalam melakukan animasi dan rendering agar video animasi yang dihasilkan dapat terlihat lebih realistis.

\section{DAFTAR PUSTAKA}

[1] Anonym. (2009). Undang-Undang Republik Indonesia Nomor 22 Tahun 2009. [ online] tersedia di: http://www.hukumonline.com, di akses pada 15 januari 2016.

[2] A.I. Paramitha, Animasi 3D Kisah Ayu Intan Permai. Skripsi Program Studi Sistem Informasi Sekolah Tinggi Manajemen Informatika Dan Komputer Stimik Amikom. Purwokerto 2014.

[3] Anonym. ( 2015 ). Definisi blender. [online]. tersedia di: http://www.blender.org, di akses pada tanggal 1 Mei 2015.

[4] Anonym. (2015) Definisi MakeHuman, [online] tersedia di: http//www.makehuman.org, diakses pada tanggal 22 november 2015

[5] Beane A. 2012. 3D Animation Essentials, John Wiley and Sons, Inc. Indianapolis

[6] Chan K. 2007. A Proposed Character Animation Workflow For Digital Production Arts With Preparation For Cloth Dynamics, jurnal Clemson University.

[7] S. Adnan, Analisa Faktor-Faktor Penyebab Kecelakan Lalu Lintas Di jalan Tol Jakarta-Cikampek. Skripsi Program S1 Kesehatan Masyarakat Universitas islam Negri Syarif hidayatullah. Jakarta, 2010.

[8] T.K. Handayani, Pembuatan Animasi 3D Oragan Reproduksi Manusia Untuk Meningkatkan Pemahaman Remaja Dalam Penyuluhan Kesehatan Reproduksi Remaja. Skripsi Program Studi Informatika Fakultas Sains Dan Teknologi Universitas Islam Negeri Syarif Hidayatullah. Jakarta, 2011.

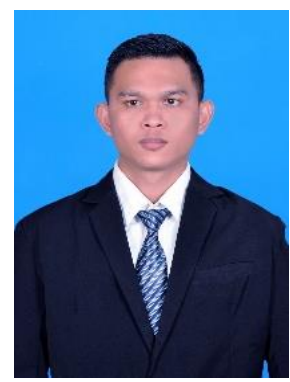

Sekilas dari penulis dengan nama lengkap, I Made Andika Sanjaya, lahir di Dondomon, Provinsi Sulawesi Utara. Anak ke-2 dari 3 bersaudara. Dengan pendidikan Sekolah Dasar Negeri 2 Ibolian. Kemudian melanjutkan ke Sekolah Menengah Pertama Negeri 1 Werdi Agung. Kemudian melanjutkan ke Sekolah Menengah Kejuruan SMK Cokroaminoto Kotamobagu. Setelah lulus tahun 2011 melanjutkan ke Perguruan Tinggi di Universitas Sam Ratulangi dengan mengambil Jurusan Teknik Informatika. Pada Bulan September 2015, penulis membuat Skripsi demi memenuhi syarat Sarjana (S1) dengan penelitian berjudul Rancang Bangun Animasi 3 Dimensi Penyebab Kecelakaan Lalu Lintas ( Studi Kasus : Polres Bolaang Mongondow ) yang dibimbing oleh dua dosen pembimbing yaitu Arie S.M Lumenta, ST., MT dan Brave A. Sugiarso, ST., M.T. sehingga pada tanggal 25 November 2016 penulis resmi lulus di Teknik Informatika Universitas Sam Ratulangi Manado dan menyandang gelar Sarjana Komputer dengan predikat Sangat Memuaskan. 